\title{
O ressentimento na filosofia de Nietzsche
}

Resumo: O ressentimento ocupa papel de destaque na filosofia de Nietzsche. Para Nietzsche, o ressentimento não é apenas um sentimento individual, mas sim, um fenômeno fisiopsicológico, no qual os indivíduos incapazes de lidar com a própria fraqueza, fomentam e recriam sentimentos negativos em decorrência de sua situação existencial. Nietzsche analisa os efeitos e as consequências do ressentimento à moral moderna, aos valores e ao indivíduo. Tendo como base os apontamentos trazidos pelo filósofo alemão, o presente artigo busca compreender os significados do ressentimento na obra de Nietzsche.

Palavras-chave: moral - Nietzsche - ressentimento - valores

\section{Resentment in Nietzsche's Philosophy}

Abstract: Resentment is an important concept in Nietzsche's thought. For Nietzsche, resentment is not just an individual feeling, but a physiopsychological phenomenon, in which individuals unable to deal with their own weakness, foster and recreate negative feelings as result of their existential situation. Nietzsche analyzes the effects and consequences of resentment in moral and values. Having the notes brought by the German philosopher, this article seeks to understand the meanings of resentment in Nietzsche's work interpreting this concept.

Keywords: moral - Nietzsche - resentment - values

\footnotetext{
${ }^{1}$ Doutorando pelo Programa de Pós-Graduação em Sociologia e Ciência Política na área de concentração Ciência Política pela Universidade Federal de Santa Catarina. Possui graduação em Relações Internacionais pela Universidade Federal de Santa Catarina e mestrado em Sociologia Política pela Universidade Federal de Santa Catarina.
} 
Friedrich Wilhelm Nietzsche (1844-1900) foi o filósofo que desnudou os significados e as consequências do ressentimento e articulou-os aos valores morais, mostrando sua importância e seus desdobramentos na formação social e no comportamento dos homens. Nietzsche nasceu perto de Leipzig, na Alemanha, seu pai, pastor protestante, morreu quando o jovem filósofo tinha apenas cinco anos. O filósofo orientou seus estudos universitários para o campo das línguas antigas e da filosofia clássica e, ao entrar em contato com o pensamento de Schopenhauer, passou a dedicar-se com maior ênfase à filosofia.

Ao longo de sua vida Nietzsche apresentou inúmeros problemas de saúde, entretanto nada o impediu de trabalhar obstinadamente ao longo de seu tempo saudável na construção de um pensamento filosófico que influenciaria diretamente os pensadores do século XX e XXI, refletindo acerca da vida, do ressentimento, da moral e, principalmente, sobre os valores e a gênese destes. Ao final de sua vida mergulhou na demência e, no final do século XIX, faleceu. Nietzsche atribuiu papel de proeminência às suas dores e problemas em seu esclarecimento sobre o ressentimento, como ele mesmo afirma: "A ausência de ressentimento, a clarividência sobre o ressentimento - quem sabe se, em última análise, por elas devo também ser grato à minha longa enfermidade?" 2 .

O ressentimento ocupa um papel de destaque na obra do filósofo, principalmente, no que tange à crítica aos valores morais da modernidade. Por mais que Nietzsche não tenha sido o primeiro ${ }^{3}$ intelectual a teorizar sobre o ressentimento, no pensamento de Nietzsche o conceito de ressentimento toma novos contornos a ponto de se tornar referência obrigatória em qualquer caracterização do termo. Em suas obras o filósofo alemão discorre sobre a moral e os conflitos intrínsecos a ela, questionando a essência dos valores a partir de uma metodologia genealógica, na qual o ressentimento assume um papel na gênese da moral hodierna. Em seus escritos acerca da moral, inicialmente o autor passa a examinar propriamente os valores morais, concomitantemente com necessidade de questioná-los e estudá-los, para somente depois inserir a questão do ressentimento.

Destacam-se os motivos que levaram Nietzsche a questionar a moral e a elaborar um pensamento que visava a examinar pontos considerados quase inquestionáveis em sua época:

$\mathrm{Na}$, assim chamada, 'ciência da moral' faltava precisamente, por mais que isso pareça estranho, o próprio problema da moral e não havia mesmo a suspeita da existência de algum problema. Aquilo que os filósofos chamam 'fundamento da moral' e aquilo que pretendiam, não era visto em verdadeira grandeza, mais que uma forma sapiente da boa fé na moral dominante, um novo meio de exprimir esta moral, portanto, um estado de fato nos limites de uma moralidade determinada ou ainda, em última análise, uma espécie de negação, que uma tal moral pudesse ser concebida corno problema; e, em cada caso, o contrário de um desânimo, de uma análise, de uma contestação, de uma vivissecção desta boa-fé. ${ }^{4}$

\footnotetext{
${ }^{2}$ NIETZSCHE, Ecce Homo, p. 19.

3 Antes mesmo de Nietzsche, outros filósofos, como Michel de Montaigne, haviam teorizado acerca do ressentimento. O ensaio $A$ covardia é mãe da crueldade de Montaigne é um bom exemplo de teorização que retrata a questão do ressentimento.

${ }^{4}$ NIETZSCHE, Além do Bem e do Mal, p. 99.
} 
Perante tal passagem, se percebe que em Nietzsche a busca pela verdade e pela desconstrução dos pressupostos estabelecidos é um dos motores de toda a sua obra. $\mathrm{O}$ autor mostra-se consciente da originalidade de sua pesquisa e justifica a necessidade de uma análise cirúrgica da moral e dos valores. Tais questionamentos sobre os possíveis problemas dos valores e da moral trouxeram uma nova exigência filosófica para o estudo da moral e dos valores, como Nietzsche mesmo afirma:

Enunciemo-la, esta nova exigência: necessitamos de uma crítica dos valores morais, o próprio valor desses valores deverá ser colocado em questão para isto é necessário um conhecimento das condições e circunstâncias nas quais nasceram, sob as quais se desenvolveram e se modificaram (moral como consequência, como sintoma, máscara, tartufice, doença, malentendido; mas também moral como causa, medicamento, estimulante, inibição, veneno), um conhecimento tal como até hoje nunca existiu nem foi desejado. ${ }^{5}$

Partindo destes questionamentos, o autor estabelece os caminhos metodológicos que se adequam a uma análise dos valores morais. Para Nietzsche, o que existe é uma genealogia da formação dos valores, uma evolução. $O$ autor observa na metodologia genealógica a melhor forma de analisar a correlação de forças e contingências que guiaram o surgimento da moral e a progressão da formação dos valores.

Logo, o 'desenvolvimento' de uma coisa, um uso, um órgão, é tudo menos o seu progressus em direção a uma meta, menos ainda um progressus lógico e rápido, obtido com um dispêndio mínimo de forças — mas sim, a sucessão de processos de subjugamento que nela ocorrem, mais ou menos profundos, mais ou menos interdependentes, juntamente com as resistências que a cada vez encontram, as metamorfoses tentadas com o fim de defesa e reação, e também os resultados de ações contrárias bem-sucedidas. Se a forma é fluida, o 'sentido' é mais ainda... Mesmo no interior de cada organismo não é diferente: a cada crescimento essencial do todo muda também o 'sentido' dos órgãos individuais - em certas circunstâncias a sua ruína parcial, a sua diminuição em número (pela destruição dos componentes intermediários, por exemplo) pode ser um signo de crescente força e perfeição. ${ }^{6}$

Em sua metodologia genealógica, Nietzsche compreende a moral como um processo de luta entre forças. O filósofo mostra-se contrário a toda natureza metafísica dos valores humanos, afirmando que os valores são meras criações humanas determinadas a partir de conflitos de forças e de poder. A verdade, para Nietzsche, também é advinda de uma criação dos homens, que corresponde às conveniências humanas. Deste modo, a filosofia de Nietzsche articula o "conhecimento e a moral, a fim de chegar a um ponto de vista crítico

\footnotetext{
${ }^{5}$ NIETZSCHE, Genealogia da Moral, p. 12.
}

${ }^{6}$ NIETZSCHE, Genealogia da Moral, p. 61. 
de ambos. Nietzsche não oferece a seus leitores o porto seguro de um pensamento ortodoxo, uma proposta sobre a verdade, uma certeza qualquer" 7 .

Contudo, se Nietzsche recusa a perspectiva de uma verdade absoluta sobre as coisas, qual critério o Nietzsche utiliza para estabelecer seu pensamento? Para o filósofo alemão, o critério utilizado é a vida, não a sua preservação, mas sim, a vida enquanto potência, enquanto superação de obstáculos e fortificação ${ }^{8}$. Posto isto, é por meio do critério vida que o autor objetiva analisar os juízos de valor e o valor destes valores, para assim alcançar a origem das palavras bom e mau e entender como estes valores atuam na vida dos indivíduos.

(...) sob que condições o homem inventou para si os juízos de valor 'bom' e 'mau'? e que valor têm eles? Obstruíram ou promoveram até agora o crescimento do homem? São indícios de miséria, empobrecimento, degeneração da vida? Ou, ao contrário, revela-se neles a plenitude, a força, a vontade da vida, sua coragem, sua certeza, seu futuro? ${ }^{9}$

Nietzsche, ao analisar os valores e a origem das palavras bom e mau, em seu uso moral, compreende que os valores nem sempre são impostos pelos mais fortes aos mais fracos, ao contrário, para ele a moral é invenção dos fracos, sendo que as noções de bom e mau funcionam como uma vingança espiritual contra os mais fortes, operando como recurso de domesticação dos homens. Ao conceituar e entender esta vingança espiritual dos fracos em relação aos fortes, Nietzsche desenvolve a ideia de ressentimento, conceito que será imprescindível para entender como os fracos passaram a dominar os mais fortes, como explica Lefranc:

\begin{abstract}
Nietzsche introduziu no vocabulário filosófico uma nova noção para designar esta força dos fracos, este voltar-se sobre si de um poder entravado que acaba, no entanto, por se impor aos 'melhores': ele utiliza a partir de Além do Bem e do Mal o termo francês ressentiment que assim se torna de alguma forma um termo técnico para a crítica genealógica. ${ }^{10}$
\end{abstract}

$\mathrm{Na}$ extensão de suas obras, Nietzsche utiliza o termo ressentimento como uma incapacidade de reação acompanhada por uma fraqueza de assimilação, correspondendo a um fenômeno fisiológico, que se adjetiva por motivar a vingança espiritual dos fracos, assim como uma vontade de imposição moral, que guiará a genealogia da formação dos valores.

O termo 'ressentimento' corresponde, assim, já no interior da filosofia de Nietzsche, a um problema fisiológico, à falta de forças de um organismo cansado para reagir frente às intempéries da vida e que também não consegue digerir os sentimentos ruins que produz, apresentando, ora pela fraqueza que

\footnotetext{
${ }^{7}$ KHEL, Ressentimento, p. 110.

${ }^{8}$ Neste sentido, existe uma unanimidade entre os comentadores utilizados neste trabalho sobre a vida como critério, imperativo no pensamento de Nietzsche.

${ }^{9}$ NIETZSCHE, Genealogia da Moral, p. 09.

${ }^{10}$ LEFRANC, Compreender Nietzsche, p. 155.
} 
gera tais sentimentos, ora pela presença deles, uma desordem psíquica que o impede de viver efetivamente o presente. Nesse organismo, a percepção da própria fraqueza e o sentimento de frustração que se segue a obstrução da ação gera um rancor, uma vontade de ferir e produzir sofrimento naquele que o destratou. Toma posse dele uma sede de efetuar aquela vingança que sua fraqueza não permite realizar. ${ }^{11}$

Além desta assimilação, Nietzsche liga o termo ao direito e à moral, ou seja, a uma análise social. Ressalta-se o fato de que em Nietzsche, "quando o ressentimento extrapola a mera descrição de uma fraqueza fisiológica, ele não se caracteriza mais pela inação, mas, ao contrário, como uma forma de ação" ${ }^{12}$. Em Nietzsche, o ressentimento se expressa não, exclusivamente, como uma inibição da ação, mas também como um imperativo dentro da moral. O filósofo alemão tipifica o ressentimento como um movimento que possui o adjetivo de tornar-se dominante, que advoga em diversas áreas, como no direito, na política, na religião e, principalmente, na moral.

A moral - onde é que pensam que ela possa ter seus mais temidos e mais rancorosos advogados? Aqui está um frustrado que não tem espírito suficiente para se regozijar e precisamente cultura suficiente para sabê-lo. Aborrecido, desgostoso, só se despreza a si mesmo; possuídos de pequena herança, infelizmente está privado da suprema consolação, a 'bênção do trabalho', o esquecimento de si nas 'lides cotidianas': esse homem tem, no fundo, vergonha de sua existência - talvez, ainda por cima, albergue alguns pequenos vícios - e que, por outro lado, não pode impedir de se corromper cada vez mais, de se tornar sempre mais vaidoso e irritadiço em virtude de leituras a que não tem direito, ou a uma sociedade demasiado intelectual para seu estômago: esse homem, envenenado até a medula- porque para um malogrado dessa natureza o espírito se torna veneno, a cultura se torna veneno, a propriedade se torna veneno, a solidão se torna veneno - acaba por cair num estado habitual de vingança, de vontade de vingança (...). ${ }^{13}$

Seguindo seu pensamento neste aforismo, Nietzsche mostra a necessidade do ressentido em dar valor à sua decadência e à sua fraqueza, mostrando que é na moral onde este sujeito encontra o saciar desta necessidade. O ressentido vê na moral do ressentimento um anestésico para sua impotência e um meio de fomentar e efetivar a sua vingança imaginária.

De que acham vocês que ele tem necessidade, necessidade imperiosa, para dar a si mesmo aparência de superioridade sobre aqueles que têm mais

\footnotetext{
${ }^{11}$ PASCHOAL, Nietzsche e o Ressentimento, p.33.

12 PASCHOAL, Nietzsche e o Ressentimento, p.36.

${ }^{13}$ NIETZSCHE, A Gaia Ciência, p. 233.
} 
espírito do que ele, para dar-se o prazer de uma vingança consumada pelo menos na imaginação? Sempre a moralidade (pode-se apostar!), sempre as grandes palavras da moral, sempre as cantilenas de justiça, de sabedoria, de santidade, de virtude (...) Que me compreendam bem: acontece, às vezes, que, desses inimigos natos do espírito, se desenvolvem esses raros exemplos de humanidade que povo venera sob nome de santo e sábio; é desses homens que surgem esses monstros de moral que fazem barulho, que fazem história $(\ldots) .{ }^{14}$

O escrito de Nietzsche que retrata abertamente o ressentimento e como a moral do ressentimento atua como vingança dos fracos é a Genealogia da Moral, livro no qual o autor descreve a história de formação e reformação da moral moderna. O ressentimento neste livro fica claro como a posição daqueles que foram cúmplices de sua própria derrota, de modo que, a moral provinda do ressentimento atua como uma vingança imaginária destes contra os fortes, criando e gerando valores para prover as necessidades que a vingança imaginária demanda. Neste escrito, o Nietzsche constata a dicotomia entre duas morais, a escrava, provinda do ressentimento, e a moral nobre, que deriva da confiança e da autoafirmação dos valores. A vingança imaginária é denominada por Nietzsche como rebelião escrava na moral. Nas palavras do autor:

A rebelião escrava na moral começa quando o próprio ressentimento se torna criador e gera valores: o ressentimento dos seres aos quais é negada a verdadeira reação, a dos atos, e que apenas por uma vingança imaginária obtém reparação. Enquanto toda moral nobre nasce de um triunfante Sim a si mesma, já de início, a moral escrava diz Não a um 'fora', um 'outro', um 'não-eu' - e este Não é seu ato criador. Esta inversão do olhar que estabelece valores - este necessário dirigir-se para fora, em vez de voltar-se para si - é algo próprio do ressentimento: a moral escrava sempre requer, para nascer, um mundo oposto e exterior, para poder agir em absoluto - sua ação é no fundo reação. ${ }^{15}$

O ressentido passa a eleger inimigos "e precisamente nisto será seu feito, sua criação: ele concebeu o 'inimigo mau', e isto, como conceito básico, a partir do qual também elabora, como imagem equivalente, um 'bom' - ele mesmo" 16. A criação conceitual do outro como inimigo mau é peculiar ao ressentido como mecanismo de defesa moral, permitindo que ele se mantenha em uma dialética na qual ele é o bom, e nisto incide a moral negativa do ressentimento, em classificar o diferente ou o externo como mau. Nietzsche utiliza-se de uma metáfora entre as ovelhas e as aves de rapina, para explicar como tal fenômeno ocorre.

Mas voltemos atrás: o problema da outra origem do 'bom', do bom como concebido pelo homem do ressentimento, exige sua conclusão. - Que as

\footnotetext{
${ }^{14}$ NIETZSCHE, A Gaia Ciência, p. 233-234.

${ }^{15}$ NIETZSCHE, Genealogia da Moral, p. 26.

${ }^{16}$ NIETZSCHE, Genealogia da Moral, p. 28.
} 
ovelhas tenham rancor às grandes aves de rapina não surpreende: mas não é motivo para censurar às aves de rapina o fato de pegarem as ovelhinhas. E se as ovelhas dizem entre si: 'essas aves de rapina são más; e quem for o menos possível ave de rapina, e sim o seu oposto, ovelha - este não deveria ser bom?', não há o que objetar a esse modo de erigir um ideal, exceto talvez que as aves de rapina assistirão a isso com ar zombeteiro, e dirão para si mesmas: 'nós nada temos contra essas boas ovelhas, pelo contrário, nós as amamos: nada mais delicioso do que uma tenra ovelhinha'. ${ }^{17}$

As noções de bom e mau funcionam como uma vingança espiritual contra os mais fortes, já que atributos como a força, a superioridade e, até mesmo, a diferença passam a ser condenados como expressões do mal e a fraqueza elevada à categoria de virtude dos bons. O ressentido busca acusar e classificar seus inimigos maus; agenciando uma dívida espiritual simplesmente por não ser forte, ou por ser ovelha e não ave de rapina. Em virtude de sua condição existencial, o ressentido busca amputar a força do forte em um ideal imaginário de justiça, buscando abolir a diferença e excluir singularidades. A moral do ressentido promove o direito à crueldade como uma compensação, ou como uma dívida que o ressentido cobra por sua falta de virtude ${ }^{18}$. Trata-se, nas palavras de Nietzsche, de "sacralizar a vingança sob nome de justiça - como se no fundo a justiça fosse apenas uma evolução do sentimento de estar ferido - de depois promover, como a vingança, todos os afetos reativos" ${ }^{19}$. Posto isto, elucidamos o fragmento que diz: "essas aves de rapina são más; e quem for o menos possível ave de rapina, e sim, o seu oposto, ovelha - este não deveria ser bom?", pois, neste momento, não se compreende apenas como más as aves de rapina, mas sim, tudo o que não for ovelha. Assim a dialética do ressentimento passa a classificar os sujeitos como bons e maus, não indo, exclusivamente, contra os fortes, mas também contra a diferença.

Nietzsche, ao explicitar a inversão dos valores que o espírito do ressentimento promoveu, trata de conceituar a oposição bom e ruim para definir como a sede de vingança do ressentimento transformou-a em bom e mau. Para o autor, a oposição bom e ruim possuía inicialmente um caráter de utilidade, nas palavras do autor: "O phatos da nobreza e da distância, como já disse, o duradouro, dominante sentimento global de uma elevada estirpe senhorial, em sua relação com uma estirpe mais baixa, com um 'sob' - eis a origem da oposição 'bom' e 'ruim'."20 Contudo, diferentemente da oposição bom e ruim, a oposição bom e mau, quando advinda do espírito do ressentimento, fomenta a necessidade de afirmar o outro como mau, recriminando e distribuindo culpa, imputando erros e delegando responsabilidades ao outro, para assim, o ressentido se afirmar como bom. Tal fenômeno pode ser verificado, no pensamento de Nietzsche, quando o filósofo analisa a inversão de valores promovida a partir do espírito do ressentimento:

\footnotetext{
${ }^{17}$ NIETZSCHE, Genealogia da Moral, p. 32.

18 Tal fato pode ser percebido no livro Ressentimento, de Maria Rita Khel. Podemos afirmar de forma genérica, que a autora, ao correlacionar o ressentimento com questões presentes na psicanálise, realiza, nesse escrito, um valoroso trabalho na interpretação do ressentimento como falta, ou seja, como uma dívida a ser cobrada pelo ressentido em virtude de sua condição em relação ao outro. Cf. KHEL, Ressentimento, 2014.

${ }^{19}$ NIETZSCHE, Genealogia da Moral, p. 57.

${ }^{20}$ NIETZSCHE, Genealogia da Moral, p. 17.
} 
Foram os judeus [cristãos e ressentidos] que, com apavorante coerência, ousaram inverter a equação de valores aristocrática (bom $=$ nobre $=$ poderoso $=$ belo $=$ feliz caro aos deuses), e com unhas e dentes (os dentes do ódio mais fundo, o ódio impotente) se apegaram a esta inversão, a saber, 'os miseráveis somente são os bons, apenas os pobres, impotentes, baixos são bons, os sofredores, necessitados, feios, doentes são os únicos beatos, os únicos abençoados, unicamente para eles há bem-aventurança - mas vocês, nobres e poderosos, vocês serão por toda eternidade os maus, os cruéis, os lascivos, os insaciáveis, os ímpios serão também eternamente os desventurados, malditos e danados!...' . ${ }^{21}$

Esta passagem de Nietzsche explicita a necessidade do espírito do ressentimento em denominar o outro como poderoso e responsável pela impotência do eu para, posteriormente, transformar este pensamento em uma dialética na qual a impotência do ressentido é a prova de que ele é bom e o outro é mau. Para Nietzsche, o cristianismo e a moral cristã retiraram o uso utilitarista das noções de bom e ruim para inserir um novo significado ao bom, delineando os conceitos de bom e mau a partir do espírito do ressentimento.

Ao apresentar a moral nobre em contrapartida à moral do ressentimento, Nietzsche não extingue a existência de ressentimento no coração dos homens nobres, contudo, a perspectiva que estes homens adotam para lidar com o ressentimento diferencia-se do modo como o fraco lida com tal afeto. $\mathrm{O}$ fraco ressentido sente a necessidade de alimentar o seu ressentimento, ao passo que o nobre não cultiva tal sentimento em seu coração.

Mesmo o ressentimento do homem nobre, quando nele aparece, se consome e se exaure numa reação imediata, por isso não envenena: por outro lado, nem sequer aparece, em inúmeros casos em que é inevitável nos impotentes e fracos. Não conseguir levar a sério por muito tempo seus inimigos, suas desventuras, seus malfeitos inclusive - eis o indício de naturezas fortes e plenas, em que há um excesso de força plástica, modeladora, regeneradora, propiciadora do esquecimento (no mundo moderno, um bom exemplo é Mirabeau, que não tinha memória para os insultos e baixezas que sofria, e que não podia desculpar, simplesmente porque - esquecia). Um homem tal sacode de si, com um movimento, muitos vermes que em outros se enterrariam; apenas neste caso é possível, se for possível em absoluto, o autêntico 'amor aos inimigos'. ${ }^{22}$

Em Nietzsche, o ressentimento é consequência das restrições dos instintos em razão da vida em sociedade. É o adjetivo dos fracos que identificam sua fraqueza com os valores da bondade, humildade e altruísmo, de modo que os fortes e singulares, que eles não se atrevem a enfrentar, pareçam maus, mesquinhos e egoístas. Para Nietzsche, o fraco quando ressentido só consegue se afirmar negando o forte, ao qual não consegue se igualar. Tal

${ }^{21}$ NIETZSCHE, Genealogia da Moral, p. 23.

22 NIETZSCHE, Genealogia da Moral, p. 28. 
operação mental faz o ressentido evitar contato com tudo o que é não eu, sua única força consiste em acusar os fortes. A moral do ressentido transforma em mérito a fraqueza e a impotência e cria as condições para os fortes e singulares serem dominados em um ideal de homogeneização estabelecido pela moral do ressentimento. A moral do ressentimento, por mais que se trate de uma moral constituída a partir da fraqueza, se faz com o intuito de criar as condições favoráveis para um tipo fraco de sujeito predominar sobre os outros tipos de homens.

O ressentimento passa a assumir traços de um problema social, na medida em que corresponde a uma moral, a uma concepção de justiça e a um modo de intervenção social, na qual os indivíduos portadores de vitalidade ou diferentes passam a sentir-se mal por simplesmente serem o que são, se notando culpados por estarem fora do rebanho dos bons. ${ }^{23}$ Perante esta moral, Nietzsche deixa clara sua indignação com as exigências e os movimentos psicológicos que a moral do ressentimento difunde entre os homens.

Exigir da força que não se expresse como força, que não seja um quererdominar, um querer-vencer, um querer-subjugar, uma sede de inimigos, resistências e triunfos, é tão absurdo quanto exigir da fraqueza que se expresse como força. ${ }^{24}$

Este movimento é a forma de dominação do ressentimento, o modo como o ressentimento torna-se dominante justamente por realizar uma operação mental nos sujeitos, por meio da moral. A vitória do ressentido ocorre quando os fortes apenas podem ser julgados pela perspectiva dos fracos.

O estabelecimento de sua moral é a vingança imaginária, que tem sucesso quando os fortes não podem julgar a si mesmos senão da perspectiva dos fracos. Os fortes são vencidos quando se deixam envolver pelo mundo imaginário da moral do ressentimento. $\mathrm{Na}$ moral luta-se pelo poder da definição: quem se deixa julgar por quem. ${ }^{25}$

Ademais, destaca-se a metáfora realizada por Nietzsche comparando o ressentido com um pregador de uma falsa igualdade, ou como aranhas venenosas, que buscam atrair e capturar seguidores para a sua vingança imaginária.

Eu vos dou, portanto, este conselho, meus amigos: desconfiai de todos aqueles nos quais o instinto de punir é poderoso. (...). Desconfiai daqueles que falam muito de sua própria justiça. $\mathrm{Na}$ verdade, não é só de mel que se alimentam essas almas. E a si mesmas se chamam de boas e justas, não esqueçais que para serem filisteus falta-lhes apenas o poder. (...) Aranhas

\footnotetext{
${ }^{23}$ Em outras palavras, dentro da metáfora de Nietzsche sobre as ovelhas e as aves de rapina, tal afirmação sobre o ressentimento pode ser explicada da seguinte maneira: $O$ ressentimento faz as aves de rapina se sentirem culpadas por serem o que são, ou meramente por não serem ovelhas.

${ }^{24}$ NIETZSCHE, Genealogia da Moral, p. 32-33.

25 SAFRANSKI, Nietzsche, biografia de uma tragédia, p. 276.
} 
venenosas que se dizem louvadoras da vida, embora permaneçam ocultas nos esconderijos, afastadas da vida; é à sua maneira de fazer o mal. ${ }^{26}$

As aranhas, como mencionado nesta passagem de Assim Falava Zaratustra, seriam os seres do ressentimento, do ódio e do desejo de vingança que querem gozar da tortura perante os agentes ao qual não podem igualar-se. As aranhas, recheadas de ressentimento, açulam em seus semelhantes um inexorável desejo de vingança maquiado por ideais como justiça e igualdade, tentando aguçar no coração dos demais sujeitos o sentimento de que estes também são injustiçados e precisam lutar pela igualdade e justiça (do ressentimento).

Zaratustra correlaciona o veneno da vingança (da sede de vingança) à ideia de justiça, em especial, à concepção de justiça que se apoia na noção de igualdade ou numa 'vontade de igualdade' entendida como um nivelamento do homem e como uma forma de ódio, injúria e, por fim, de interdição de tudo que se destaca ou que é diferente. ${ }^{27}$

Como é possível observar, ao longo das passagens de Nietzsche acerca do ressentimento e da moral escrava, o ressentimento não se apresenta apenas como um problema pessoal dos indivíduos, mas também social, "em que ele é claramente associado a uma acepção social que prega uma igualdade em detrimento de toda possibilidade de tipos diferentes de homem"28. Desta forma, a partir de um processo de universalização, a sede de vingança recebe o nome de justiça, "institucionalizando aquele princípio de igualdade que, de resto, conflui numa massificação disforme, espalhando-se por todo o corpo social como o veneno de uma tarântula que invade a vítima" ${ }^{29}$.

Ao discorrer de sua crítica à modernidade e aos valores cristãos, Nietzsche insere um dos pontos sobre os malefícios do ressentimento e de sua moral. Para o filósofo, a moral do ressentimento intrínseca aos valores cristãos, por ter realizado um movimento de homogeneização sobre os homens e sua cultura, sobre seu pensar e em seu modo de agir, impediu o surgimento de novas morais e de novos tipos de homens. Nietzsche, em $O$ Anticristo, deixa claro a sua insatisfação com a moral cristã, com o monotonoteísmo fornecido por esta moral e com a falta de criação do próprio homem sobre seus valores morais que, ao longo de dois milênios, pautou-se apenas em uma única moral para definir suas ações entre boas e más:

Quase dois milênios decorridos e nem um único deus novo! Mas apenas subsistindo sempre e como que por direito, como um ultimatum e maximum da força criadora do divino, do creator spiritus no homem, esse miserável Deus do monotonoteísmo cristão! Esse híbrido produto ruinoso, feito de zero, de conceito e de contradição, em que a sua sanção encontra todos os instintos de décadence, todas as cobardias e fadigas da alma! ${ }^{30}$

\footnotetext{
${ }^{26}$ NIETZSCHE, Assim Falava Zaratustra, p. 138-139.

27 PASCHOAL, Nietzsche e o Ressentimento, p. 39.

28 PASCHOAL, Nietzsche e o Ressentimento, p. 39.

29 PASCHOAL, Nietzsche e o Ressentimento, p. 72.

${ }^{30}$ NIETZSCHE, O Anticristo, p. 17.
} 
Nietzsche adiciona a culpa e a má consciência como características do ressentido, sendo uma arma de dominação e um veneno para fazer com que os fortes e singulares sintam-se mal pela sua vitalidade ou por sua diferença. Como arma, atenuamos o fato de que os pregadores da moral do ressentimento querem que os fortes se sintam mal pela sua força, que sintam culpa por tornarem-se o que são, impregnando preceitos morais para o sujeito sentir-se mal. O ressentido sente a superioridade e a singularidade continuamente como uma ofensa à sua situação existencial, contudo, por meio da moral do ressentimento, busca um prêmio de consolação: que os superiores padeçam no remorso e na culpa pelo dano moral causado.

Em relação ao fraco, tal veneno funciona como um anestésico que permite a ele suportar seu sofrimento sem sucumbir a ele e, em relação ao forte, como um entorpecimento que visa enfraquecê-lo. Em ambos os casos, o propósito é um nivelamento do homem, a produção do rebanho universal e impedir o aparecimento de tipos diferentes de homem. ${ }^{31}$

Diante destes pontos, elucida-se a ideia de má consciência e de ressentimento em Nietzsche, de modo que é importante conferir a precisão estratégica que tais termos ganham nos escritos do autor alemão para entender as nuances que os termos apresentam. Inicialmente, atenua-se que a expressão ressentimento pode ser entendida como "a designação de uma vontade de poder que busca tornar-se dominante sobre as demais" 32 , fator que não compactua com expressão má consciência nos escritos do filósofo. Inicialmente, nos escritos de Nietzsche, o termo má consciência aparece como um antagonismo à boa consciência, sendo que a boa consciência permite ao indivíduo agir sem restrições e rir até do que lhe causa dano, ao passo que, a má consciência atua como um sentimento de culpa, fator que limita a ação dos indivíduos. A má consciência pode ser entendida, em outras passagens, como a luta interna dos indivíduos entre os preceitos estabelecidos pela moral do ressentimento e as vontades fisiológicas do sujeito. Neste segundo caso, é importante destacar o uso do termo acompanhado dos preceitos do cristianismo, no qual ele aparece associado entre as ações realizadas pelos indivíduos em desconformidade com a moral estabelecida pela igreja. Em outros escritos, em especial, em Assim Falava Zaratustra e em Além do Bem e do Mal, o termo aparece como uma vergonha interior por uma ação realizada. ${ }^{33}$

Agora, retornando para a análise de Nietzsche, dos valores e da moral, destaca-se que o filósofo, ao basilar seu pensamento e ao realizar sua análise da moral, desconecta o avanço moral do avanço técnico. Para o filósofo, os valores não evoluem, concomitantemente, com o ordenamento do progresso. Na axiologia de Nietzsche, a ordem do homem moderno, fundamentada no conforto e na passividade, é inferior à de tempos mais antigos, quando se valorizava a virtude e o fortalecimento humano.

\footnotetext{
31 PASCHOAL, Nietzsche e o Ressentimento, p. 72.

32 PASCHOAL, Nietzsche e o Ressentimento, p. 151.

${ }_{33}$ Tal mapeamento e percepção destes conceitos nas obras de Nietzsche podem ser encontrados com riquezas de detalhes em: PASCHOAL, Nietzsche e o Ressentimento.
} 
Ao contrário do que hoje se crê, a humanidade não representa uma evolução para algo de melhor, de mais forte ou de mais elevado. O 'progresso' é simplesmente uma ideia moderna, ou seja, uma ideia falsa. O europeu de hoje vale bem menos do que o europeu do Renascimento; desenvolvimento contínuo não é forçosamente elevar-se, aperfeiçoar-se, fortalecer-se. ${ }^{34}$

Nietzsche, por mais que realize uma extensa crítica à modernidade e aos valores de sua época, não é contra a existência de valores, mas, simplesmente a favor dos valores que contribuem para aumentar o potencial da vida e a autossuperação do homem, pois a valorização e engrandecimento da vida são os critérios éticos utilizados por Nietzsche ao formular suas ideias.

(...) o desejo de sempre novas expansões das distâncias entre a própria alma, o desenvolvimento de estados sempre mais elevados, mais variados, distantes, maiores, tendentes a alturas ignotas, logo à elevação do tipo 'homem', o incessante triunfo do homem sobre si mesmo para adotar em sentido supermoral uma fórmula moral. ${ }^{35}$

A crítica de Nietzsche acerca da moral não deve ser compreendida como uma crítica especulativa voltada às ideias ou para o próprio saber, mas sim, como um estudo da origem das motivações profundas que estão no nascimento da moral e dos valores. Para combater a moral do ressentimento, o filósofo insere a ideia de imoralismo, que será produto dos seres ativos e singulares. O imoralismo, em uma descrição genérica, seria a moral dos seres que portam a capacidade de criar seus próprios valores, operando uma transvaloração dos valores, ${ }^{36}$ a fim de amenizar os efeitos do ressentimento, que se encontram impregnados e correlacionados com a moral cristã,${ }^{37}$ provinda do ressentimento. Na ética que se depreende do pensamento de Nietzsche, a má consciência e a culpa assumem contornos brandos na consciência dos sujeitos de modo que o principal mandamento ético de Nietzsche é: tornate quem tu és, fator que estimula parte dos homens a serem fortes e singulares, apesar disso, Nietzsche mantém seu pensamento sabendo que nem todos poderão ser fortes, pois de acordo com o autor nem todos os homens são iguais.

Além dos pontos destacados neste artigo, é imprescindível afirmar que, por mais que Nietzsche proponha uma moral nobre em contrapartida à moral do ressentimento, o autor não realiza uma crítica moral em relação a outra moral, pois a luta de Nietzsche é contra a existência de uma única moral para todos os indivíduos e em favor de novos tipos de homens, novas morais e novos modos de se ver a vida.

Para Nietzsche um dos problemas ressentimento é que este germina de uma vontade que cultiva a impotência, incapaz de proporcionar a expansão criativa das forças vitais, de

\footnotetext{
34 NIETZSCHE, O Anticristo, p. 4.

35 NIETZSCHE, Além do Bem e do Mal, p. 193.

$36 \mathrm{O}$ conceito de transvaloração dos valores pode ser compreendido como uma crítica de Nietzsche em relação à fundamentação transcendente dos valores. Para Nietzsche, os valores não apresentam um caráter metafísico, pois são frutos das avaliações humanas. Assim, de forma genérica, ponderamos que o processo de transvaloração dos valores consiste na criação, por parte dos indivíduos, de novas referenciais valorativas.

${ }^{37}$ Nesta referência a moral cristã entende-se a moral da modernidade, seja ela religiosa ou não, tendo em vista a própria genealogia da moral moderna, a qual se fundamentou nos valores cristãos.
} 
novos tipos de homens e de novas formas de conceber o mundo, tornando-se assim uma ação corrosiva interior, que encontra na moralidade sua fórmula, pois a incapacidade humana de expressar o poder de ação criativa gera no indivíduo um mal-estar existencial fundamentado no rancor perante toda constituição vital, criativa e abundante. No pensamento do filósofo, enquanto as práticas da moral escrava, provindas do ressentimento, consistirem em justificar e valorizar a fraqueza, os fracos estarão destinados ao ressentimento e à fraqueza. Para solucionar tais problemas, Nietzsche propõe que devemos repensar nossa maneira de ver o mundo, transcendendo os valores morais pré-estabelecidos pelo ressentimento, ou em outras palavras: "Devemos mudar nossa maneira de ver - para chegar finalmente, talvez demasiado tarde, a mudar nossa maneira de sentir". ${ }^{38}$

\section{Referências bibliográficas}

KHEL, Maria Rita. Ressentimento. São Paulo: Casa do Psicólogo, 2014.

LEFRANC, Jean. Compreender nietzssche. Trad. Lucia M. Endlich Orth, São Paulo: Vozes. 2005.

NIETZSCHE, Friedrich. Assim falava Zaratustra: Um livro para todos e para ninguém. Trad. Mário Ferreira dos Santos. São Paulo - SP. Vozes. 2011.

Genealogia da moral: Uma polêmica. Trad. Paulo César Lima de Souza. São Paulo - SP. Companhia das Letras. 2009.

Além do bem e do mal ou prelúdio de uma filosofia do futuro. Trad. Márcio Pugliesi. Curitiba: Hemus livraria, distribuidora e editora s.a., 2001.

. Ecce Homo: Como alguém se torna o que é. Trad. Artur Morão. LusoSofia: press. 2008.

. A Gaia Ciência. Trad. Antonio Carlos Braga. São Paulo: Escala, 1997.

. Aurora. Trad. Antonio Carlos Braga. São Paulo: Escala. 2007.

O Anticristo. Trad. Arthur Mourão. São Paulo: Lusofia Press. 1997. Disponível em: http://docplayer.com.br/4323807-O-anticristo-friedrich-nietzsche-tradutor-artur-moraowww-lusosofia-net.html Acesso em 05 de março de 2017.

PASCHOAL, Edmilson. Nietzsche e o Ressentimento. São Paulo: ed. Humanitas, 2015.

SAFRANSKI, Rüdiger. Nieţssche, biografia de uma tragédia. Trad. Lya L. Luft. São Paulo: Geração Editorial, 2005.

38 Nietzsche, Aurora, p. 79. 